\title{
EFEITO DE GLYPHOSATE E IMAZAQUIN NA COMUNIDADE BACTERIANA DO RIZOPLANO DE SOJA (Glycine max (L.) MERRILL) E EM CARACTERÍSTICAS MICROBIOLÓGICAS DO SOLO ${ }^{(1)}$
}

\author{
Jerri Édson Zilli( ${ }^{(2)}$, Gloria Regina Botelho( ${ }^{(3)}$, Maria Cristina Prata \\ Neves $^{(4)} \&$ Norma Gouvêa Rumjanek ${ }^{(4)}$
}

\begin{abstract}
RESUMO
Práticas culturais, como a aplicação de agrotóxicos, podem interferir diretamente na comunidade microbiana do solo e naquela associada às raízes vegetais. Os efeitos, no entanto, são complexos e, na maioria das vezes, de difícil detecção, quando se utilizam técnicas convencionais na avaliação. Por outro lado, o recente desenvolvimento e utilização de métodos moleculares, baseados no DNA, têm permitido melhorar a avaliação desses efeitos muitas vezes negativos. Este trabalho teve como objetivo avaliar alterações provocadas pela aplicação de herbicidas à base de glyphosate e imazaquin no $\mathrm{C}$ da biomassa microbiana do solo (C-BMS), respiração basal do solo (RBS) e quociente metabólico $\left(q \mathrm{CO}_{2}\right)$, bem como na comunidade bacteriana associada ao rizoplano de soja (Glycine max (L.) Merril), por meio das técnicas de eletroforese em gel com gradiente desnaturante (DGGE) e análise da região espaçadora intergênica ribossomal (RISA). Realizou-se um experimento em casa de vegetação com solo coletado em área com histórico de cultivo de soja e aplicação desses herbicidas. A C-BMS, $\mathrm{RBS}$ e $q \mathrm{CO}_{2}$ foram avaliadas antes da aplicação dos herbicidas e aos 2, 14, 30 e 62 dias depois desta. A comunidade bacteriana associada ao rizoplano de soja foi avaliada por DGGE e RISA aos 14, 30 e 62 dias após a aplicação dos herbicidas. Os resultados mostraram que ambos os herbicidas não ocasionaram alterações significativas no teor de $\mathbf{C}$ da biomassa microbiana do solo, na respiração basal do solo e no quociente metabólico; contudo, ocasionaram alterações na comunidade bacteriana associada ao rizoplano de soja, na forma de restrição do crescimento de determinadas bactérias e estímulo de
\end{abstract}

\footnotetext{
(1) Trabalho extraído da Tese de Doutorado do primeiro autor. Recebido para publicação em outubro de 2006 e aprovado em julho de 2007.

(2) Pesquisador da Embrapa Roraima. BR 174, km 8, Distrito Industrial, Caixa Postal 133, CEP 69307-970 Boa Vista (RR). E-mil: zilli@cpafrr.embrapa.br

${ }^{(3)}$ Professora, Laboratório de Microbiologia do Solo, Universidade Federal do Mato Grosso - UFMT. Avenida Fernando Corrêa s/n, Coxipó, CEP 78060-900 Cuiabá (MT). E-mail: gbotelho.rlk@terra.com.br

(4) Pesquisadora da Embrapa Agrobiologia. BR 465 km 7, Bairro Ecologia, Caixa Postal 74500, CEP 23890-000 Seropédica (RJ). Emails: mcpneves@cnpab.embrapa.br,norma@cnpab.embrapa.br
} 
outras, em todas as coletas realizadas. As similaridades entre os perfis bacterianos os tratamentos com herbicidas e controle foram inferiores a $55 \% \mathrm{em}$ todas as coletas.

Termos de indexação: herbicidas, DGGE, RISA, carbono da biomassa microbiana, respiração basal do solo e quociente metabólico.

\title{
SUMMARY: EFFECT OF GLYPHOSATE AND IMAZAQUIN ON THE SOYBEAN RHIZOPLANE BACTERIAL COMMUNITY AND MICROBIOLOGICAL SOIL CHARACTERISTICS
}

\begin{abstract}
Cultural practices, such as herbicide application, can directly interfere with microbial communities of soil and roots. These effects are complex and difficult to be detected, especially when analyzed by conventional methods. On the other hand, the recent development and use of molecular, DNA-based methods allows for a more accurate evaluation of these, often negative, effects. The purpose of this study was to assess the effects of glyphosate and imazaquin-based herbicides, widely used in Brazil, on soil microbial biomass carbon, soil basal respiration and metabolic quotient, and on microbial community associated to rhizoplane of soybean roots. A greenhouse experiment was conducted using soil from a soybean plantation treated with constant applications of these herbicides. Soil microbial biomass carbon, basal soil respiration and metabolic quotient were determined before herbicide application and 2, 14, 30, and 62 days afterwards. The bacterial community associated to rhizoplane was analyzed by Denaturing Gradient Gel Electrophoresis (DGGE) and Ribossomal Interspacer Analysis (RISA) 14, 30 and 62 days after herbicide application. Results indicated no significant changes in soil microbial biomass carbon, basal respiration and metabolic quotient as a result of the herbicides application. However, both herbicides changed the bacterial profile in the rhizoplane during the experimental period. DGGE and RISA analysis detected absence, as well as presence of some bacteria in the herbicide treatment compared to the control. The bacterial profile similarity between the herbicide treatment and control was less than $55 \%$ in all periods analyzed.
\end{abstract}

Index terms: herbicides, DGGE, RISA, microbial biomass carbon, soil basal respiration, metabolic quotient.

\section{INTRODUÇÃO}

Plantas anuais e perenes exsudam, por meio do sistema radicular, até $50 \%$ dos compostos de C fotossintetizados (Grayston \& Vaughan, 1996). Essa exsudação mantém o equilíbrio ecológico entre os microrganismos na rizosfera, o que pode restringir o desenvolvimento de fitopatógenos e contribuir para a atividade de microrganismos benéficos, como os promotores de crescimento vegetal, solubilizadores de fosfato e fixadores de $\mathrm{N}_{2}$ (Beyeler et al., 1999; O'Donnell et al., 2001; Salles et al., 2002; Botelho \& Hagler, 2006).

No entanto, práticas culturais, como a aplicação de agrotóxicos, podem interferir diretamente na estrutura da comunidade microbiana do solo e naquela associada às raízes vegetais (Kennedy, 1999).

Do ponto de vista ambiental, tanto os herbicidas à base de glyphosate como de imazaquin, amplamente utilizados no Brasil, são considerados de moderada toxicidade, principalmente devido à baixa mobilidade e, também, porque apenas plantas e microrganismos possuem as rotas metabólicas onde eles atuam. O glyphosate atua na rota do ácido chiquímico, inibindo a produção dos aminoácidos fenilalanina, tirosina e triptofano e outros compostos secundários, como fitoalexinas (Bentley, 1990), e o imazaquin, na rota dos aminoácidos ramificados: valina, leucina e isoleucina (Duggleby \& Pang, 2000).

No solo, a molécula de glyphosate, que é polar e apresenta três grupamentos funcionais (amina, carboxilato e fosfonato), sofre reações de adsorção específicas por meio de pontes de hidrogênio, pontes co-ordenadas com íons de $\mathrm{Fe}$ e $\mathrm{Al}$ e $\mathrm{Cu}$ (McBride \& Kung, 1989; Undabeytia et al., 1996; Jonge \& Jonge, 1999) e reações covalentes de elevada especificidade, em função da afinidade do grupamento fosfonato com cargas de superfície de argilas e outros colóides (Glass, 1987). Já a molécula do imazaquin apresenta caráter anfotérico com dois grupos funcionais ionizáveis: carboxil e quinolínico, o que faz a molécula comportarse como um íon orgânico nos solos tropicais, em função da faixa de $\mathrm{pH}$ entre 4,0 e 6,0 (Stougaard et al., 1990). Como os solos de regiões tropicais apresentam predominantemente cargas de superfícies $\mathrm{pH}$ dependentes e baixo teor de matéria orgânica, a molécula fica adsorvida por longos períodos (Rocha et al., 2002). 
A degradação desses dois herbicidas no solo depende essencialmente da ação microbiana (Amarrante Júnior et al., 2002; Rezende et al., 2005). O glyphosate é degradado em condições tanto aeróbicas quanto anaeróbicas, sendo aparentemente duas as vias principais: a primeira envolve a clivagem da molécula, produzindo glioxilato e o ácido aminometil-fosfônico, e a segunda, a produção de sarcosina pela quebra da ligação C-P por enzimas C-P liases, produzidas, por exemplo, por Agrobacterium radiobactere Enterobacter aerogenes (Rueppel et al., 1977; Amarrante Júnior et al., 2002). Para o imazaquin, informações sobre microrganismos biodegradadores, mineralização ou vias metabólicas envolvidas em sua degradação ainda não estão disponíveis (Cantwell et al., 1989; Rezende et al., 2005).

Apesar de serem considerados herbicidas pouco tóxicos ao ambiente, tanto o glyphosate quanto o imazaquin podem interferir na estrutura da comunidade microbiana do solo, seja pela ação direta em um determinado grupo microbiano, seja por vantagens competitivas que conferem a outros (Descalzo et al., 1998; Kremer et al., 2005). Por exemplo, o herbicida glyphosate aplicado em plantas de soja geneticamente modificadas e convencionais ocasionou aumento da colonização das raízes por Fusarium spp. e, em conseqüência, a incidência da doença causada por esse patógeno, na própria soja e, em especial, na cultura em sucessão (Kremer, 2003; Kremer et al., 2005). Esse efeito sinergístico do glyphosate com Fusarium spp. advém da inibição que esse herbicida provoca em rizobactérias antagônicas ao fungo - exemplo: Pseudomonas spp. do grupo fluorescentes; da inibição da produção de fitoalexinas nas plantas; e do aumento da exsudação de aminoácidos e carboidratos no sistema radicular, que favorece o desenvolvimento de alguns microrganismos, como o próprio Fusarium spp. (Kremer, 2003; Kremer et al., 2005).

Efeitos como os supracitados, no entanto, ocorrem sempre de forma complexa e, na maioria das vezes, são de difícil detecção, sobretudo quando se utilizam apenas técnicas convencionais, como a mensuração da biomassa microbiana do solo e o plaqueamento em meio de cultivo para a avaliação dos efeitos.

O uso de técnicas de avaliação da comunidade microbiana baseadas no DNA tem revelado que a interação entre plantas e microrganismos, além de ser complexa, é muito importante para o adequado desenvolvimento da planta (Shen, 2000). Utilizando DGGE, Sessitsch et al. (2004) mostraram que o herbicida glufosinato de amônio e plantas de canola geneticamente modificadas resistentes a esse herbicida interferiram na comunidade bacteriana da rizosfera, quando comparada à planta isogênica. Nesse sentido, diversos estudos têm mostrado que a avaliação do impacto de agrotóxicos sobre os microrganismos do solo, utilizando tais técnicas, é importante para estimar os efeitos sobre os microrganismos e o ambiente, bem como para avaliar a capacidade de degradação da molécula do produto (Kent \& Triplett, 2002; Lynch et al., 2004).

Este trabalho teve como objetivo avaliar alterações provocadas pela aplicação de herbicidas à base de glyphosate e imazaquin no teor de $\mathrm{C}$ da biomassa microbiana do solo (C-BMS), na respiração basal do solo (RBS) e no quociente metabólico $\left(q \mathrm{CO}_{2}\right)$, assim como na comunidade bacteriana associada ao rizoplano de soja (Glycine max (L.) Merril), por meio das técnicas de eletroforese em gel com gradiente desnaturante (DGGE) e análise da região espaçadora intergênica ribossomal (RISA).

\section{MATERIAL E MÉTODOS}

\section{Descrição do experimento}

Aproximadamente $100 \mathrm{~kg}$ de solo foram coletados na profundidade de 0-20 cm em uma área de lavoura de soja em sistema de semeadura direta em Londrina (PR), localizada no campo experimental da Embrapa Soja (latitude de $23^{\circ} 11^{\prime}$ S e longitude de $51^{\circ} 11^{\prime} \mathrm{W}$ ). Esse solo foi classificado como Latossolo Vermelho distroférrico com textura muito argilosa (630 $\mathrm{g} \mathrm{kg}^{-1}$ de argila, $70 \mathrm{~g} \mathrm{~kg}^{-1}$ de areia e $300 \mathrm{~g} \mathrm{~kg}^{-1}$ de silte) e apresentou as seguintes características químicas: pH 5,6; matéria orgânica $19,6 \mathrm{~g} \mathrm{~kg}^{-1} ; \mathrm{Al}^{3+}$ $0,0 \mathrm{cmol}_{\mathrm{c}} \mathrm{dm}^{-3} ; \mathrm{Ca}^{2+} 6,9 \mathrm{cmol}_{\mathrm{c}} \mathrm{dm}^{-3} ; \mathrm{Mg}^{2+}$ $6,7 \mathrm{cmol}_{\mathrm{c}} \mathrm{dm}^{-3} ; \mathrm{H}_{2} \mathrm{PO}_{4}^{-}+\mathrm{HPO}_{4}{ }^{2-} 90 \mathrm{mg} \mathrm{dm}{ }^{-3} ; \mathrm{e} \mathrm{K}^{+}$ $580 \mathrm{mg} \mathrm{dm}^{-3}$ (Embrapa, 1997). O histórico de cultivo dessa área incluía a semeadura de soja, trigo e milho e a aplicação de herbicidas, principalmente à base de glyphosate e do grupo químico das imidazolinonas.

Com o solo coletado, foi realizado um experimento em casa de vegetação na Embrapa Agrobiologia (Seropédica-RJ) sob condições controladas, entre os meses de novembro de 2002 e janeiro de 2003. O delineamento experimental utilizado foi em blocos ao acaso, com três repetições e três tratamentos: $2,2 \mathrm{mg} \mathrm{kg}^{-1}$ de herbicida à base de glyphosate $(\mathrm{N}$ (fosfometil) glicina), que corresponde a 1,4 kg ha-1 de ingrediente ativo (i.a.); $0,2 \mathrm{mg} \mathrm{kg}^{-1}$ de herbicida a base de imazaquin (ácido 2-[4,5-diidro-4-metil-4-(1metiletil)- 5 - oxo-1- H - i midazol-2-il] - 3 quinolinacarboxílico), que corresponde $0,15 \mathrm{~kg} \mathrm{ha}^{-1}$ aplicados ao solo; e um controle sem herbicida. As doses de $1,4 \mathrm{~kg} \mathrm{ha}^{-1}$ i.a. do glyphosate e a $0,15 \mathrm{~kg} \mathrm{ha}^{-1}$ do imazaquin representam valores normalmente recomendados para a cultura da soja.

Soluções aquosas dos herbicidas foram aplicadas ao solo (1:10 v/v; herbicida: água), utilizando um pulverizador manual. Posteriormente, o solo foi homogeneizado e acomodado em vasos plásticos (aproximadamente $1 \mathrm{~kg}$ ). Sementes de soja (cv. BR46) foram inoculadas com uma mistura das estirpes de Bradyrhizobium japonicum (SEMIA 5079) e B. elkanii (SEMIA 5019) (concentração de $6 \times 10^{5}$ células/ semente, dose normalmente recomendada para a 
cultura) e semeadas 24 h após aplicação dos herbicidas. A irrigação das plantas foi realizada com água destilada, conforme a necessidade. Antes da aplicação dos herbicidas e aos 2, 14, 30 e 62 d após aplicação (DAP) foram coletadas amostras de solo nos vasos e, aos 14, 30 e 62 DAP, além de solo, amostras de raízes. Cada coleta constituiu-se de três repetições (três vasos) para cada tratamento. Os vasos coletados foram descartados após retirada do material.

\section{Determinação da C-BMS, RBS e $q \mathrm{CO}_{2}$}

A determinação do carbono da biomassa microbiana do solo (C-BMS) foi realizada pelo método de fumigação e extração (Vance et al. 1987), com o uso de $20 \mathrm{~g}$ de solo, fumigação com 1,0 mL $\mathrm{CHCl}_{3}$ aplicado diretamente sobre o solo da amostra (De-Polli \& Guerra, 1997; 1999) e extração com 50 mL de $\mathrm{K}_{2} \mathrm{SO}_{4}$ a $0,5 \mathrm{~mol} \mathrm{~L}^{-1}$. O cálculo do C-BMS (mg kg-1 de CBMS no solo) foi realizado por meio das fórmulas: C$\mathrm{BMS}=\mathrm{FC} \mathrm{kc}-1$, em que $\mathrm{FC}=\mathrm{CSF}-\mathrm{CSNF}$, sendo $\mathrm{CSF}$ o teor de C extraído do solo fumigado, CSNF o teor de C extraído do solo não fumigado e kc-fator de correção (utilizado valor de 0,33). O CSF ou CSNF $=(\mathrm{Vb}-\mathrm{Va})$ CSFA 0,003 $50(8 \mathrm{Ms})^{-1}$, em que $\mathrm{Vb}$ - volume (mL) de $\left(\mathrm{NH}_{4}\right)_{2} \mathrm{Fe}\left(\mathrm{SO}_{4}\right)_{2} \cdot 6 \mathrm{H}_{2} \mathrm{O}$ (SFA) gasto na titulação da solução do ensaio em branco; Va - volume (mL) de $\left(\mathrm{NH}_{4}\right)_{2} \mathrm{Fe}\left(\mathrm{SO}_{4}\right)_{2} \cdot 6 \mathrm{H}_{2} \mathrm{O}$ (SFA) gasto na titulação da solução do ensaio com a amostra; CSFA = concentração do SFA (mol L-1) e, M= massa da amostra de solo seco (g). Para estimar a respiração basal do solo (RBS), seguiu-se o procedimento descrito por Jenkinson \& Powlson, (1976), utilizando-se frações de $50 \mathrm{~g}$ de solo incubadas hermeticamente em frascos de vidro na presença de $10 \mathrm{~mL}$ de $\mathrm{NaOH}$ a $0,5 \mathrm{~mol} \mathrm{~L}^{-1}$ por 5 dias. $\mathrm{O}$ cálculo da $\mathrm{RBS}\left(\mathrm{mg} \mathrm{kg}^{-1} \mathrm{~h}^{-1} \mathrm{C}-\mathrm{CO}_{2}\right.$ no solo) foi realizado pela fórmula: $\mathrm{RBS}=\mathrm{Vb}-\mathrm{Va} \mathrm{CHCl}$ $61000 \mathrm{Ms}^{-1} \mathrm{~T}^{-1}$, em que, $\mathrm{Vb}$ - volume de $\mathrm{HCl}(\mathrm{mL})$ gato na titulação do $\mathrm{NaOH}$ do ensaio em branco; $\mathrm{Va}$ volume de $\mathrm{HCl}(\mathrm{mL})$ gasto na titulação do $\mathrm{NaOH}$ do ensaio com a amostra, $\mathrm{CHCl}$, concentração do $\mathrm{HCl}$ $\left(\mathrm{mol} \mathrm{L}^{-1}\right), \mathrm{Ms}$ - massa de solo incubado seco (g); e T tempo de incubação (h). O quociente metabólico $\left(q \mathrm{CO}_{2}\right)$ ( $\mu \mathrm{g} \mathrm{kg}^{-1} \mathrm{~h}^{-1}$ de $\mathrm{C}-\mathrm{CO}_{2}$ do C-BMS), por sua vez, foi estimado pela razão entre a respiração basal do solo e o C da biomassa microbiana (Anderson \& Domsch, 1990), seguindo a fórmula:

$$
q \mathrm{CO}_{2}=\mathrm{RBS} / \mathrm{C}-\mathrm{BMS} 1000 .
$$

\section{Obtenção das células microbianas do rizoplano de soja e extração do DNA}

Raízes finas das plantas de soja foram cortadas e lavadas por 5 min em solução salina de $\mathrm{NaCl}\left(8,5 \mathrm{~g} \mathrm{~L}^{-1}\right.$, esterilizada) e secas em papel absorvente esterilizado. Em seguida, pesou-se 1,0 g de raízes de cada repetição, que foi acondicionado em tubos cônicos de $50 \mathrm{~mL}$ com $20 \mathrm{~mL}$ de solução salina de $\mathrm{NaCl}$ a $8,5 \mathrm{~g} \mathrm{~L}^{-1}$, esterelizada, os quais foram agitados horizontalmente por $30 \mathrm{~min}$ a $200 \mathrm{rpm}$. Desse extrato, retiraram-se $8 \mathrm{~mL}$, que foram centrifugados a $8.000 \mathrm{rpm}$ por 30 min a $4{ }^{\circ} \mathrm{C}$, e o precipitado formado foi armazenado a $20^{\circ} \mathrm{C}$ por 12 h. Para extração do DNA, seguiu-se o protocolo descrito por Schwieger \& Tebbe (1998) e adaptado por Xavier et al. (2004), utilizando o tampão de lise TES (NaCl, $\mathrm{Na}_{2}$-EDTA, Tris/HCl e SDS) e fenol: clorofórmio: álcool isolamílico.

\section{Análise do 16S rDNA por DGGE}

$\mathrm{Na}$ amplificação do $16 \mathrm{~S}$ rDNA, cada $35 \mu \mathrm{L}$ da reação consistiu de $1 \mu \mathrm{L}$ de DNA microbiano extraído, $10 \mathrm{mmol} \mathrm{L}^{-1}$ de tampão Tris-HCl, $3,5 \mathrm{mmol} \mathrm{L}^{-1}$ de $\mathrm{MgCl}_{2}, 0,2 \mathrm{mmol} \mathrm{L}^{-1}$ de dNTP, 1,4 U de Taq DNA polimerase (Invitrogen Cat No. 11615-010) e $0,2 \mu \mathrm{mol} \mathrm{L} \mathrm{L}^{-1}$ de cada um dos iniciadores $968 \mathrm{~F}-\mathrm{GC} \mathrm{e}$ 1401R (Gelsomino et al., 1999). Um volume de 12 a $20 \mu \mathrm{L}$ de cada amostra de DNA amplificado foi aplicado em gel desnaturante de poliacrilamida a $6 \%(\mathrm{~N}$ -

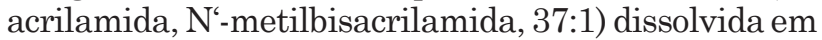
tampão TAE 0,5X (20 mmol L-1 de Tris-base $\mathrm{pH} 7,8$; $10 \mathrm{mmol} \mathrm{L}^{-1}$ de acetato de sódio; 0,5 $\mathrm{mmol} \mathrm{L}^{-1} \mathrm{de} \mathrm{Na}_{2^{-}}$ EDTA). O gradiente desnaturante utilizado foi de 50-65 \%, obtido com o uso de duas soluções: uma contendo apenas poliacrilamida e a outra, poliacrilamida, 7 mol L-1 de uréia e $40 \mathrm{HO} \% \mathrm{~V} / \mathrm{V}$ de formamida. A eletroforese foi realizada no sistema $\operatorname{Dcode}^{T M}$ (Bio-Rad), sob voltagem constante a $120 \mathrm{~V}$ por $16 \mathrm{~h}$ a $60{ }^{\circ} \mathrm{C}$. Após a eletroforese, o gel foi corado com uma solução de Syber Gold (Molecular Probe, $\mathrm{N}^{\circ}$ Cat.S11494) a 20X e visualizado sob luz ultravioleta no sistema de fotodocumentação IMAGO (B\&L).

\section{Análise da Região Espaçadora por RISA}

Para amplificação da região intergênica, cada $20 \mu \mathrm{L}$ da reação consistiu de $1 \mu \mathrm{L}$ de DNA (aproximadamente $0,5 \mathrm{ng}), 2 \mathrm{mmol} \mathrm{L}{ }^{-1}$ de tampão Tris- $\mathrm{HCl}$, 2,5 $\mathrm{mmol} \mathrm{L}^{-1}$ de $\mathrm{MgCl}_{2}, 0,2 \mu \mathrm{mol} \mathrm{L}{ }^{-1}$ de dNTP, 1,4 U de Taq DNA polimerase (Invitrogen Cat No. 11615010) e $0,2 \mu \mathrm{mol} \mathrm{L}{ }^{-1}$ de cada um dos iniciadores FGPL123‘-38 e FGPS1490-72 (Normand et al., 1996). Um volume de 10 a $20 \mu \mathrm{L}$ de cada amostra de DNA amplificado foi aplicado em gel de poliacrilamida a $6 \%$ (N-acrilamida, N'-metilbisacrilamida, 37,5:1) dissolvida em tampão TBE $1 \mathrm{X}\left(0,1 \mathrm{~mol} \mathrm{~L}^{-1}\right.$ de Tris-base; 0,1 $\mathrm{mol} \mathrm{L}^{-1}$ de ácido bórico; $2 \mathrm{mmol} \mathrm{L}^{-1}$ de $\mathrm{Na}_{2}$-EDTA,). A eletroforese foi realizada no sistema Protean ${ }^{T M}$ (BioRad), sob voltagem constante a $60 \mathrm{~V}$ por 16 horas a $20^{\circ} \mathrm{C}$. A coloração dos géis e a captura das imagens foram realizadas como descrito anteriormente para os géis de DGGE.

\section{Análise dos dados}

Os dados gerados nos géis de DGGE e RISA foram analisados utilizando-se o coeficiente Jaccard e o método de agrupamento UPGMA, por meio do programa NTSYS-PCV. 2.10 (Applied Biostatistics). Os dados de C-BMS, respiração basal do solo e quociente metabólico foram submetidos à análise de variância a 5 \%). 


\section{RESULTADOS}

\section{Avaliação do carbono da biomassa microbiana do solo (C-BMS), da respiração basal do solo (RBS) e do quociente metabólico $\left(q \mathrm{CO}_{2}\right)$}

Aos dois dias após aplicação dos herbicidas, constatou-se que em todos os tratamentos do experimento - controle sem herbicida, aplicação de herbicida à base de glyphosate e de herbicida à base de imazaquin - houve aumento tanto do $\mathrm{C}$ da biomassa microbiana como da respiração basal do solo, comparativamente com a avaliação realizada antes da aplicação desses herbicidas (Quadro 1). Nas coletas subseqüentes, o C-BMS diminuiu pronunciadamente, chegando a valores inferiores aos observados na primeira avaliação. A RBS também seguiu essa tendência, exceto na última coleta (62 dias), quando os valores foram superiores aos obtidos antes da aplicação dos herbicidas (Quadro 1). Quanto ao quociente metabólico, ao contrário das determinações anteriores, o menor valor foi constatado antes da aplicação dos herbicidas, tendo aumentado gradativamente nas coletas subseqüentes (Quadro 1).
Não foram constatadas diferenças significativas entre os valores de $\mathrm{C}$ da biomassa microbiana do solo, respiração basal do solo e quociente metabólico obtidos nos tratamentos com os herbicidas em relação ao controle (Quadro 1), indicando que essas características não sofreram efeito desses herbicidas.

\section{Comunidade bacteriana associada ao rizoplano de soja}

As análises do 16S rDNA através do DGGE e da região intergênica 16S-23S rDNA das amostras de DNA microbiano, obtidas de raízes de soja aos 14, 30 e 62 dias após aplicação dos herbicidas, mostraram que diversas bandas detectadas no controle não foram observadas nas amostras tratadas com os herbicidas, como destacam as setas no controle aos 14 dias da figura 1a,b. Essa observação também é bastante clara no gel de RISA, no qual cerca de oito bandas ocorridas no controle, aos 14 dias, não ocorreram nos tratamentos com os herbicidas. Em outras coletas, foram detectadas bandas nas amostras tratadas com os herbicidas, que não ocorreram no controle - por exemplo, no tratamento com glyphosate aos 30 dias (Figura 1a) - e bandas que ocorreram nos dois

Quadro 1. Carbono da biomassa microbiana do solo (C-BMS), respiração basal do solo (RBS) e quociente metabólico $\left(q \mathrm{CO}_{2}\right)$ nas coletas antes e aos 2, 14, 30 e 62 dias após aplicação dos herbicidas glyphosate e imazaquin

\begin{tabular}{|c|c|c|c|c|}
\hline \multicolumn{2}{|c|}{ Tratamento } & $\mathbf{C}-\mathbf{B M S} \mathbf{S}^{(1)}$ & $\mathbf{R B S}^{(1)}$ & $q \mathrm{CO}_{2}{ }^{(1)}$ \\
\hline & & $\mathrm{mg} \mathrm{kg}^{-1}$ de $\mathrm{C}$ da BMS & $\mathrm{mg} \mathrm{kg}^{-1} \mathrm{~h}^{-1}$ de $\mathrm{C}-\mathrm{CO}_{2}$ do solo & $\mu \mathrm{g} \mathrm{kg}^{-1} \mathrm{~h}^{-1}$ de C-CO ${ }_{2}$ do C-BMS \\
\hline \multicolumn{2}{|c|}{ Antes da semeadura } & 129,7 & 0,5 & 3,86 \\
\hline \multirow[t]{3}{*}{2 dias } & Controle & 384,8 & 1,9 & 4,94 \\
\hline & Glyphosate & 379,7 & 1,7 & 4,48 \\
\hline & Imazaquin & 385,7 & 1,6 & 4,15 \\
\hline CV (\%) & & 17,0 & 38,0 & 20,90 \\
\hline \multirow[t]{3}{*}{14 dias } & Controle & 88,1 & 0,4 & 4,54 \\
\hline & Glyphosate & 112,4 & 0,5 & 4,45 \\
\hline & Imazaquin & 76,4 & 0,4 & 5,24 \\
\hline CV (\%) & & 35,0 & 25,0 & 52,00 \\
\hline \multirow[t]{3}{*}{30 dias } & Controle & 132,6 & 1,00 & 7,50 \\
\hline & Glyphosate & 107,7 & 0,7 & 6,50 \\
\hline & Imazaquin & 123,2 & 0,7 & 5,70 \\
\hline $\mathrm{CV}(\%)$ & & 17,0 & 53,0 & 21,00 \\
\hline \multirow[t]{3}{*}{62 dias } & Controle & 45,0 & 0,8 & 17,80 \\
\hline & Glyphosate & 47,0 & 0,9 & 19,10 \\
\hline & Imazaquin & 57,5 & 0,7 & 12,20 \\
\hline CV (\%) & & 25,0 & 29,0 & 67,00 \\
\hline
\end{tabular}

(1) Os valores em cada uma das coletas, dentro de cada determinação, não apresentaram diferença significativa pela análise de variância a $5 \%$. 
tratamentos com os herbicidas e não no controle - por exemplo, nas amostras com glyphosate e imazaquin aos 62 dias (Figura 1b).

Os dendrogramas obtidos com os perfis eletroforéticos dos géis de DGGE e RISA mostram que a similaridade entre as amostras do controle foi inferior a $50 \%$ com ambas as técnicas, em todas as coletas (Figura 2), indicando que, mesmo sem a presença dos herbicidas, ocorreu diferenciação entre os perfis bacterianos no rizoplano de plantas de soja ao longo do período avaliado.

Por outro lado, a similaridade entre os perfis bacterianos do rizoplano de soja dos tratamentos com os herbicidas à base de glyphosate e imazaquin, em relação ao controle, foi inferior a $55 \%$ em todas as coletas, mesmo considerando a amplitude de variação do erro-padrão entre blocos (Figura 3). Comparandose os resultados obtidos pelas duas técnicas, com exceção do tratamento com glyphosate na coleta aos 14 dias, os valores médios de similaridade foram muito semelhantes em todas as coletas, embora tenha havido tendência de os valores de similaridades obtidos a partir dos dados de RISA serem inferiores aos obtidos com os dados gerados pelo DGGE.

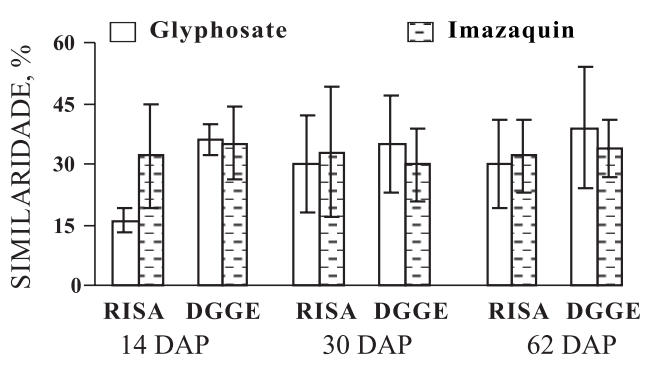

Figura 3. Similaridade dos perfis bacterianos obtidos por DGGE e RISA em amostras de rizoplano de soja cultivada em solo tratado com herbicidas à base de glyphosate e imazaquin, em relação ao tratamento controle. As barras no gráfico indicam o erro-padrão entre os blocos. (DAP: dias após aplicação dos herbicidas).
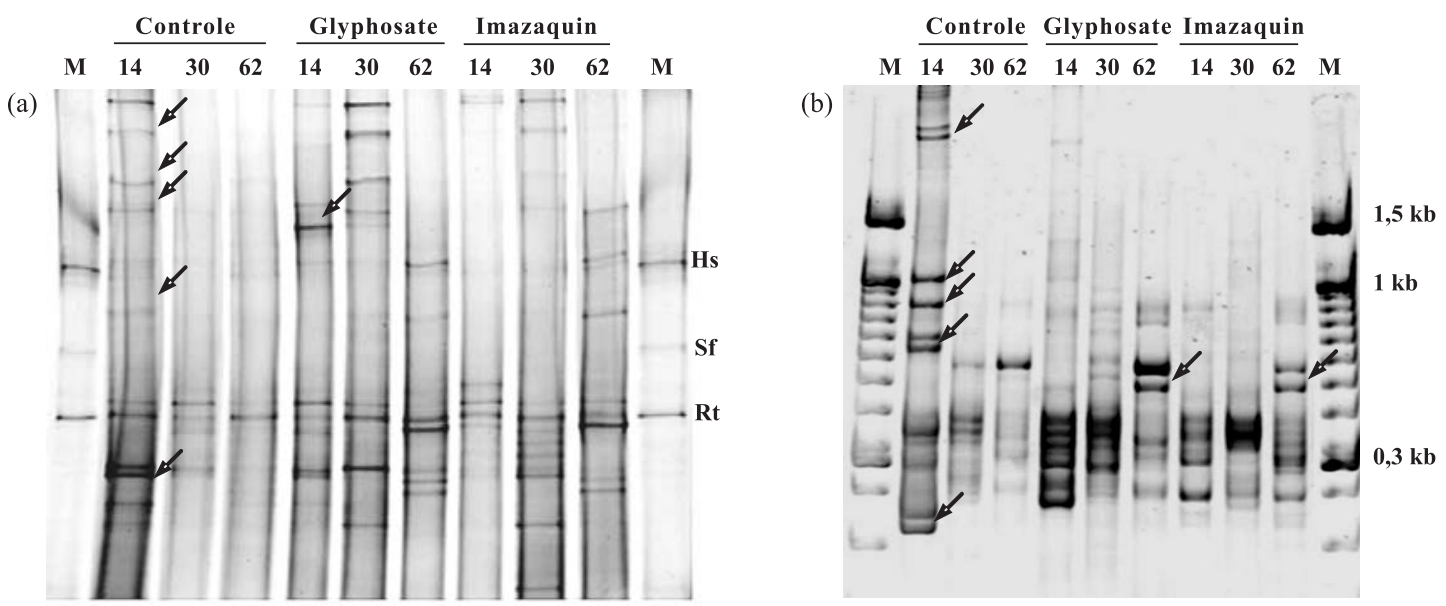

Figura 1. Exemplo de perfil bacteriano do rizoplano de soja cultivada em solo tratado com os herbicidas à base de glyphosate e imazaquin 14, 30 e 62 dias após a aplicação. (a) perfil bacteriano obtido por DGGE (M: marcador; Hs: Herbaspirillum seropedicae; Sf: Sinorhizobium fredii; Rt: Rhizobium tropici); (b) perfil bacteriano obtido por RISA (M: marcador de peso molecular - 100 bp). Obs.: as amostras dos géis são referentes apenas ao bloco 1 do experimento.

DGGE

Erro-padrão entre blocos Similaridade entre $14-30$ dias $= \pm 0,12$; $14-62$ dias $= \pm 0,07 ; 30-62$ dias $= \pm 0,11$

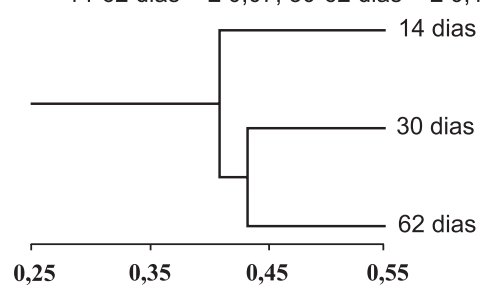

RISA

Erro-padrão entre blocos Similaridade entre $14-30$ dias $= \pm 0,12$; $14-62$ dias $= \pm 0,08 ; 30-62$ dias $= \pm 0,14$

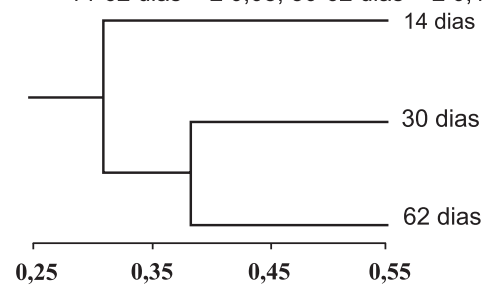

Figura 2. Similaridade entre os perfis bacterianos do rizoplano de plantas de soja obtidos com as técnicas de DGGE e RISA em amostras do tratamento controle, aos 14, 30 e 62 dias após aplicação dos herbicidas glyphosate e imazaquin. 


\section{DISCUSSÃO}

Observou-se aumento nos valores de $\mathrm{C}$ da biomassa microbiana do solo - C-BMS, na respiração basal do solo - RBS e no quociente metabólico nos primeiros dias após o início do experimento e redução nas coletas subseqüentes, independentemente dos tratamentos com herbicidas à base de glyphosate e imazaquin. Valores altos de C-BMS encontrados logo após simples homogeneização e umedecimento de amostras são freqüentemente decorrentes do fluxo de atividade da biomassa microbiana no reservatório de matéria orgânica do solo que se encontra pronto para mineralização, porém protegido química e fisicamente (Franzluebbers et al., 1996; Salinas-Garcia et al., 1997; Gonçalves et al., 2002). Por outro lado, a redução do C-BMS e RBS nas coletas subseqüentes deve ter ocorrido porque os microrganismos se multiplicaram enquanto havia substrato disponível, mas a seguir ocorreu limitação de nutrientes (Joergensen et al., 1990). O esgotamento de substratos e dos próprios nutrientes do solo, que deve ter sido acelerado com o crescimento das plantas, explica a contínua elevação do quociente metabólico ao longo do tempo (Quadro 1), indicando estado de estresse metabólico da biomassa microbiana do solo.

O efeito de herbicidas à base de glyphosate sobre o C-BMS está freqüentemente associado à capacidade de alguns microrganismos, principalmente fungos (Kremer et al., 2005), utilizarem a molécula do produto como fonte de $\mathrm{C}$ e N (Haney et al., 2000). Nesse caso, observa-se elevação dos teores de C microbiano e, muitas vezes, aumento da mineralização da matéria orgânica do solo, em função da maior atividade microbiana (Wardle \& Parkinson, 1990; Haney et al., 2000). Eventualmente, o efeito dos herbicidas sobre a biomassa microbiana do solo pode se dar por inibição da atividade microbiana. Li et al. (2004), por exemplo, observaram, em condições de campo, redução da biomassa microbiana do solo e, também, da mineralização de compostos orgânicos com aplicação do ingrediente ativo imazapyr, pertencente ao grupo químico das imidazolinonas. Especificamente, quanto ao imazaquin, apesar de pertencer ao grupo químico das imidazolinonas, amplamente utilizado no mundo todo, pouco se conhece sobre os seus efeitos nos microrganismos do solo.

Neste trabalho, o preparo do solo com homogeneização e acomodação nos vasos e a presença das plantas podem ter conferido impacto maior à biomassa microbiana do que propriamente a aplicação dos herbicidas. Isso explicaria a ausência de efeito claro desses herbicidas sobre o $\mathrm{C}$ da biomassa microbiana, a respiração basal do solo e o quociente metabólico. A ausência de efeito dos herbicidas pode também estar relacionada à sua rápida adsorção no solo, uma vez que o teor de 19,6 $\mathrm{g} \mathrm{kg}^{-1}$ de matéria orgânica, a textura muito argilosa e o $\mathrm{pH}$ abaixo de 6,0 favoreceriam esse processo para ambos os herbicidas (Glass, 1987;
Rocha et al., 2002). Estando os herbicidas adsorvidos aos colóides do solo, a ação inibitória sobre os microrganismos ficaria reduzida, não sendo quantitativamente detectada pelos métodos de avaliação da biomassa microbiana utilizados.

O efeito da planta também foi observado na comunidade bacteriana associada ao rizoplano de soja, por meio de DGGE e RISA. Nesse caso, a similaridade entre os perfis bacterianos das amostras do tratamento controle, nas três coletas (14, 30 e 62 dias), foi sempre baixa (Figura 2), indicando que a comunidade bacteriana respondeu à presença da planta, alterando-se durante o desenrolar do experimento, independentemente da presença dos herbicidas.

Resposta semelhante a essa também foi observada para as comunidades bacteriana e fúngica associadas à rizosfera de dois cultivares de milho, nas quais a complexidade da comunidade microbiana aumentou com a idade das plantas, e o estádio de coleta exerceu maior influência sobre a comunidade microbiana do que propriamente os cultivares de milho (Gomes et al., 2001, 2003). Também Sessitsch et al. (2004) observaram que a idade das plantas de canola exerceu mais efeito sobre a comunidade bacteriana associada à rizosfera do que a aplicação do herbicida glufosinato de amônio.

Entretanto, com a aplicação dos herbicidas observou-se que houve restrição ao crescimento de determinadas bactérias, isto é, ausência de certas bandas nos géis de DGGE e RISA, e também o estímulo a outras nos mesmos tratamentos (Figura 1a,b), mostrando que, devido à ação dos herbicidas, a estrutura da comunidade bacteriana foi alterada em comparação ao controle. Essa alteração da comunidade bacteriana, na forma de restrição de certas bactérias e estímulo de outras, traduziu-se em redução da similaridade entre os tratamentos com os herbicidas e o controle, que ocorreu desde os 14 até os 62 dias após aplicação dos herbicidas (Figura 3). Essa inibição provavelmente ocorreu porque, conforme já assinalado, os herbicidas testados são potentes inibidores de rotas metabólicas de produção de aminoácidos em vegetais e microrganismos (Bentley, 1990; Duggleby \& Pang, 2000).

Efeitos negativos do glyphosate sobre determinados microrganismos do solo já foram observados, por exemplo, para Azotobacter (Wachowska \& Banaszkiewicz, 1999) e Pseudomonas (Kremer et al., 2005), que são bactérias ecologicamente importantes no solo. Entretanto, também são descritos efeitos estimulantes do glyphosate, tanto em condições de casa de vegetação quanto em campo, para fungos dos gêneros Rhizoctonia (Smiley et al., 1991), Pythium (Descalzo et al., 1998), Phytophthora (Johal \& Rahe, 1984) e Fusarium (Levesque et al., 1993; Kremer, 2003; Kremer et al., 2005), os quais são causadores de doenças em várias espécies vegetais. $\mathrm{O}$ efeito do imazaquin sobre os microrganismos do solo ainda é 
pouco conhecido. É possível, porém, que ocorram efeitos severos, pois é necessário apenas pequena concentração do ingrediente ativo para inibição da rota metabólica em diversos organismos (Zohar et al., 2003). Esse desconhecimento é preocupante, pois o uso de produtos do grupo químico das imidazolinonas, ao qual o imazaquin pertence, tende a aumentar no Brasil, especialmente em lavouras de soja (Rocha et al., 2002).

Por outro lado, observou-se que ao longo do tempo não houve tendência de aumento da similaridade entre os perfis bacterianos dos tratamentos com e sem aplicação dos herbicidas, indicando que os efeitos foram prolongados ou que ocorreram de forma irreversível. Esses resultados reforçam a hipótese de que os herbicidas podem atuar sobre os microrganismos do solo por longos períodos, contrapondo, de certa forma, outras observações que indicam efeitos restritivos apenas nos primeiros dias após a aplicação (Wardle \& Parkinson, 1990).

Alterações na comunidade microbiana do solo, embora muitas vezes sejam consideradas temporárias, podem representar ruptura do equilíbrio biodinâmico no solo, interferindo diretamente na decomposição/ mineralização da matéria orgânica, ciclagem de nutrientes, supressão de doenças etc. (Kennedy, 1999). Ao longo do tempo, essas alterações podem representar a perda da qualidade do solo, ou seja, perda da capacidade de promover adequado desenvolvimento vegetal.

Além da possível irreversibilidade do efeito dos herbicidas na comunidade bacteriana, que podem ter causado morte de bactérias, pode ter ocorrido efeito da presença de metabólitos secundários, originados da degradação da molécula dos herbicidas, sobre as bactérias (Amarrante Júnior et al., 2002) e, também, seleção de bactérias resistentes ou tolerantes aos herbicidas ou seus metabólitos. Neste trabalho, utilizou-se solo de área com histórico de aplicação de herbicidas à base de glyphosate e imazaquin; dessa forma, a ocorrência de determinadas bactérias apenas nos tratamentos com os herbicidas pode indicar adaptação e seleção de microrganismos em função do uso dos herbicidas (Forlani et al., 1999).

Os resultados deste trabalho mostraram que a utilização da técnica de PCR/DGGE do 16S rDNA e PCR/RISA do espaço intergênico 16S rDNA-23S rDNA permitiu a detecção de alterações provocadas pelos herbicidas à base de glyphosate e imazaquin na comunidade bacteriana do rizoplano de plantas de soja. Isso demonstra que técnicas moleculares podem contribuir para melhor avaliação dos efeitos de herbicidas no ambiente. Esses efeitos, entretanto, podem não ser detectados por métodos tradicionais, como a mensuração de $\mathrm{C}$ da biomassa microbiana do solo, respiração basal do solo e quociente metabólico, como ocorreu neste trabalho.

A despeito das alterações provocadas pelos herbicidas à base de glyphosate e imazaquin na comunidade bacteriana, estas precisam ser oportunamente detalhadas, de modo a se entender qual é o impacto da restrição do crescimento de algumas bactérias e estímulo de outras. Especialmente com relação ao glyphosate, tem-se comprovado sua ação sinergística com determinados patógenos, como: Rhizoctonia, Pythium, Phytophthora e Fusarium (Johal \& Rahe, 1984; Smiley et al., 1991; Levesque et al., 1993; Descalzo et al., 1998; Kremer, 2003; Kremer et al., 2005). Alguns destes, além de serem resistentes ao glyphosate, o degradam, ao passo que bactérias antagônicas são sensíveis e, portanto, não conseguem sobreviver e colonizar o sistema radicular. No caso de soja transgênica, estudos têm mostrado a seleção e o aumento da colonização radicular por patógenos na própria cultura e também na cultura em sucessão, mostrando potenciais prejuízos às lavouras (Kremer, 2003; Kremer et al., 2005).

\section{CONCLUSÕES}

1. Os herbicidas à base de glyphosate e imazaquin não ocasionaram alterações significativas no teor de $\mathrm{C}$ da biomassa microbiana do solo, na respiração basal do solo e no quociente metabólico.

2. Os herbicidas à base de glyphosate e imazaquin ocasionaram alterações na comunidade bacteriana associada ao rizoplano de soja em todas as coletas realizadas, alterações estas detectadas por meio dos perfis eletroforéticos obtidos por DGGE e RISA.

3. A comunidade bacteriana associada ao rizoplano de soja alterou-se ao longo do tempo, independentemente da presença dos herbicidas.

\section{AGRADECIMENTO}

Ao doutor Alexandre Magno Brighenti dos Santos, pesquisador da Embrapa Soja, pelo auxílio na coleta das amostras de solo; e à CAPES e ao CNPq, pelo suporte financeiro.

\section{LITERATURA CITADA}

BENTLEY, R. The shikimate pathway - A metabolic tree with many branches. Crit. Rev. Biochem. Molec. Biol., 35:307384, 1990 .

AMARRANTE JÚNIOR, O.P.; SANTOS, T.C.R.; BRITO, N.M. \& RIBEIRO, M.L. Glyphosate: Propriedades, toxicidade, usos e legislação. Química Nova, 25:589-593, 2002.

ANDERSON, T.H. \& DOMSCH, K.H. Application of ecophysiological quotients $\left(q \mathrm{CO}_{2}\right.$ and $\left.q \mathrm{D}\right)$ on microbial biomasses from soils of different cropping histories. Soil Biol. Biochem., 22:251-255, 1990. 
BEYELER, M.; KEEL, C.; MICHAUX, P. \& HAAS, D. Enhanced production of indole-3-acetic acid by a genetically modified strain of Pseudomonas fluorescens CHA0 affects root growth of cucumber, but does not improve protection of the plant against Pythium root rot. FEMS Microbiol. Ecol., 28:225-233, 1999.

BOTELHO, G.R. \& MENDOÇA-HAGLER, L.C. Fluorescent Pseudomonads associated with the rhizosphere of crops An Overview. Braz. J. Microbiol., 37:401-416, 2006.

CANTWELL, J.R.; LIEBL, R.A. \& SLIFE, F.W. Biodegradation characteristics of imazaquin and imazethapyr. Weed Sci., 37:815-819, 1989.

DE-POLLI, H. \& GUERRA, J.G.M. Determinação do carbono da biomassa microbiana do solo: Método de fumigaçãoextração. Seropédica, Embrapa Agrobiologia, 1997. 10p. (Documentos, 37)

DESCALZO, R.D.; PUNJA, Z.K.; LÉVESQUE, C.A. \& RAHE, J.E. Glyphosate treatment of bean seedlings causes shortterm increases in Pythium populations and damping off potential in soils. Appl. Soil Ecol., 8:25-33, 1998.

DUGGLEBY, R.G. \& PANG, S.S. Acetohydroxyacid synthase. J. Biochem. Molec. Biol., 33:1-36, 2000.

EMPRESA BRASILEIRA DE PESQUISA AGROPECUÁRIA EMBRAPA. Manual de métodos de análise de solos. 2.ed. Rio de Janeiro, 1997. 211p.

FORLANI, G.A.; MANGIAGALLI, A.A.; NIELSEN, E.A. \& SUARDI, C.M.B. Degradation of the phosphonate herbicide glyphosate in soil: Evidence for a possible involvement of unculturable microorganisms. Soil Biol. Biochem., 31:991-997, 1999.

FRANZLUEBBERS, A.J.; HANEY, F.M. \& ZUBERER, D.A. Determination of microbial biomass and nitrogen mineralization following rewetting of dried soil. Soil Sci.Soc.Am. J., 60:1133-1139, 1996.

GELSOMINO, A.; KEIJZER-WOLTERS, A.C.; CACCO G. \& van ELSAS, J.D. Assessment of bacterial community structure in soil by polymerase chain reaction and denaturing gradient gel electrophoresis. J. Microbiol. Methods, 38:1-15, 1999.

GLASS, R.L. Phosphate adsorption by soils and clay minerals. J. Agric. Food Chem., 35:497-500, 1987.

GOMES, N.C.M.; FAGBOLA, O.; COSTA, R.; RUMJANEK, N.G.; BUCHNER, A.; MENDONÇA-HAGLER, L. \& SMALLA, K. Dynamics of fungal communities in bulk and maize rhizosphere soil in the tropics. Appl. Environ. Microbiol., 69:3758-3766, 2003.

GOMES, N.C.M.; HEUER, H.; COSTA, R.; MENDONCAHAGLER, L. \& SMALLA, K. Bacterial diversity of the rhizosphere of maize (Zea mays) grown in tropical soil studied by temperature gradient gel electrophoresis. Plant Soil, 232:167-180, 2001.

GONÇALVES, A.S.; MONTERIO, M.T.; GUERRA, J.G.M. \& DE-POLLI, H. Biomassa microbiana em amostras de solos secadas ao ar e reumedecidas. Pesq. Agopec. Bras., 37:651658, 2002.
GRAYSTON, S.J. \& VAUGHAN, D.V.D. Rhizosphere carbon flow in trees, in comparison with annual plants: The importance of root exudation and its impact on microbial activity and nutrient availability. Appl. Soil Ecol., 5:29-56, 1996.

HANEY, R.L.; SENSEMAN, S.A.; HONS, E.M. \& ZUBERER, D.A. Effect of glyphosate on soil microbial activity and biomass. Weed Sci., 48:89-93, 2000.

JENKINSON, D.S. \& POWLSON, D.S. The effects of biocida treatment on metabolism in soil - V. Method for measuring soil biomass. Soil Biol. Biochem., 8:209-213, 1976.

JOERGENSEN, R.G.; BROOKES, P.C. \& JENKINSON, D.S. Survival of the soil microbial biomass at elevated temperatures. Soil Biol.Biochem., 22:1129-1136, 1990.

JOHAL, G.S. \& RAHE, J.E. Effect of soilborn plant pathogenic fungi on the herbicidal action of glyphosate on bean seedlings. Phytopathology, 74:950-955, 1984.

JONGE, H. \& JONGE, L.W. Influence of $\mathrm{pH}$ and solution composition on the sorption of glyphosate and prochloraz to a sandy loam soil. Chemosphere, 39:753-763, 1999.

KENNEDY, A.C. Bacterial diversity in agroecosystems. Agric. Ecosyst. Environ., 74:65-76, 1999.

KENT, A.D. \& TRIPLETT, E.W. Microbial communities and their interactions in soil and rhizosphere ecosystems. Ann. Rev. Microbiol., 56:211-236, 2002.

KREMER, R. Soil biological processes are influenced by Roundup Ready soybean production. Phytopathology, 93:104, 2003.

KREMER, R.J.; MEANS, N.E. \& KIM, S. Glyphosate affects soybean root exudation and rhizosphere microorganisms. Intern. J. Environ. Anal. Chem., 85:1165-1174, 2005.

LEVESQUE, C.A.; RAHE, J.E. \& EAVES, D.M. Fungal colonization of glyphosate-treated seedlings using a new root plating technique. Mycol. Res., 97:299-306, 1993.

LI, Q.; ALLEN, H.L. \& WOLLUM II, A.G. Microbial biomass and bacterial functional diversity in forest soils: Effects of organic matter removal, compaction, and vegetation control. Soil Biol. Biochem., 36:571-579, 2004.

LYNCH, J.M.; BENEDETTI, A.; INSAM, H.; NUTI, M.P.; SMALLA K.; TORSVIK, V. \& NANNIPIERI, P. Microbial diversity in soil: Ecological theories, the contribution of molecular techniques and the impact of transgenic plants and transgenic microorganisms. Biol Fert. Soils, 40:363385,2004

MCBRIDE, M. \& KUNG, K.H. Complexation of glyphosate and related ligands with iron (III). Soil Sci. Soc. Am. J., 53:1668-1673, 1989.

NORMAND, P.; PONSONNET, C.; NESME, X.; NEYRA, M. \& SIMONET, P. ITS analysis of prokariotes. In: AKKERMANS, D.L.; van ELSAS, J.D. \& BRUIJN, F.J., eds. Molecular microbial ecology manual. Dordrecht, Kluwer Academic Publishers, 1996. p.1-12. 
O'DONNELL, A.G.; SEASMAN, M.; MACRAE, A.; WAITE, I. \& DAVIES, J.T. Plants and fertilizers as drivers of change in microbial community structure and function in soils. Plant Soil, 232:135-145, 2001.

REZENDE, M.; BARBOSA, A.M.; VASCONCELOS, A.F.D.; HADDAD, R. \& DEKKER, R.F.H. Growth and production of laccases by the ligninolytic fungi, Pleurotus ostreatus and Botryosphaeria rhodina, cultured on the herbicide, Scepter (imazaquin). J. Basic Microbiol., 45:465-474, 2005.

ROCHA, W.S.D.; REGITANO, J.B.; ALLEONI, L.R.F. \& TORNISIELO, V.L. Sorption of imazaquin in soils with positive balance of charges. Chemosphere, 49:263-270, 2002.

RUEPPEL, M.L.; BRIGHTWELL, B.B.; SCHAEFER, J. \& MARVEL, J.T. Metabolism and degradation of glyphosate in soil and water. J. Agric. Food Chem., 25:517-528, 1977.

SALINAS-GARCIA, J.R.; HONS, F.M. \& MATOCHA, J.E. Longterm effects of tillage and fertilization on soil organic matter dynamics. Soil Sci. Soc. Am. J., 61:152-159, 1997.

SALLES, J.F.; SOUZA, F.A. \& van ELSAS, J.D. Molecular methods to assess the diversity of Burkholderia species in environmental samples. Appl. Environ. Microbiol., 68:1595-1603, 2002.

SCHWIEGER, F. \& TEBBE, C.C. A new approach to utilize PCR-single-strand-conformation polymorphism for $16 \mathrm{~S}$ rRNA gene-based microbial community analysis. Appl. Environ. Microbiol., 64:4870-4876, 1998.

SESSITSCH, A.; GYAMFI, S.; TSCHERKO, D.; GERZABEK, M.H. \& KANDELER, E. Activity of microorganisms in the rhizosphere of herbicide treated and untreated transgenic glufosinate-tolerant and wildtype oilseed rape grown in containment. Plant Soil, 266:105-116, 2004.
SHEN, D. Beneficial microorganisms and metabolites derived from agriculture wastes in improving plant health and protection. J. Crop Prod., 3:349-366, 2000.

SMILEY, R.W., OGG, A.G. \& JAMES COOK, R. Influence of glyphosate on Rhizoctonia root rot, growth, and yield of barley. Plant Disease, 76:937-942, 1991.

STOUGAARD, R.N.; SHEA, P.J. \& MARTIN, A.R. Effect of soil type and $\mathrm{pH}$ on adsorption, mobility, and efficacy of imazaquin and imazethapyr. Weed Sci., 38:67-73, 1990.

UNDABEYTIA, T.; CHESHIRE, M. \& MCPHAIL, V. Interaction of the herbicide glyphosate with copper in humic complexes. Chemosphere, 32:1245-1250, 1996.

VANCE, E.D.; BROOKES, P.C. \& JENKINSON, D.S. An extraction method for measuring soil microbial biomass C. Soil Biol. Biochem., 19:703-707, 1987.

WACHOWSKA, U. \& BANASZKIEWICZ, T. Effect of herbicide roundup on microrganisms in the rhizosphere of grasses. Nat. Sci., 2:191-200, 1999

WARDLE, D.A. \& PARKINSON, D. Influence of the herbicide glyphosate on soil microbial community structure. Plant Soil, 122:29-37, 1990.

XAVIER, G.R.; SILVA, F.V.; ZILLI, J.E. \& RUMJANEK, N.G. Adaptação de método para extração de DNA microbiano. Seropédica, Embrapa Agrobiologia, 2004. 24p. (Documentos 171, Embrapa Agrobiologia)

ZOHAR, Y.; EINAV, M.; CHIPMAN, D.M. \& BARAK, Z Acetohydroxyacid synthase from Mycobacterium avium and its inhibition by sulfonylureas and imidazolinonas. Biochem. Biophys. Acta, 1649:97-105, 2003. 